\title{
PASIR KANDILO DAN KERIKIL PETANGIS SEBAGAI MATERIAL LOCAL TANAH GROGOT DALAM CAMPURAN BETON
}

\author{
Kandilo Sand And Gravel Petangis As Local Material Land Grogot In Mixed Concrete
}

\author{
Karmila Achmad \\ Jurusan Teknik Sipil Politeknik Negeri Balikpapan \\ Alamatkorespondensi : J1 Soekarno Hatta Km. 08, Balikpapan \\ email: milabpp@yahoo.co.id
}

\begin{abstract}
In the effort to utilize local material, some of Tanah Grogot people use mix concrete of Kandilo sand and Petangis Gravel instead of common material, Palu Sand and Palu Gravel. The characteristics of these local material have not been identified. The purpose of this research are to give data of Tanah Grogot local material's characteristic and to get the highest concrete strength for mixing variation commonly used by Tanah Grogot people, Kalimantan Timur. There are 4 variations of mixconcrete that were used i.e. Palu Sand + Palu Gravel (PPKP), Palu Sand+Petangis Gravel (PPKG), Kandilo sand + Palu Gravel (PGKP), Kandilo sand + Petangis Gravel (PKG). The results of the test show that the best average concrete strength was received by PPKG, $32.78 \mathrm{MPa}$, and the lowest average concrete strength belong to PKG, $17.05 \mathrm{MPa}$.
\end{abstract}

Keywords: Petangis gravel, local Material, Kandilo sand, Tanah Grogot

\begin{abstract}
Abstrak
Dalam upaya memanfaat material local sebagian masyarakat Tanah Grogot menggunakan campuran beton berupa pasir Kandilo dan kerikil Petangis disamping material yang umum digunakan, yaitu pasir Palu dan kerikil Palu. Untuk karakteristik dan kelayakan material local ini sebagai material bangunan belum dilakukan penelitian. Penelitian ini bertujuan untuk memberikan data terkait karakteristik material local tanah grogot dan mendapatkan kuat tekan terbaik untuk perpaduan material bangunan yang umum digunakan oleh masyarakat Tanah Grogot, Kalimantan Timur. Ada 4 variasi campuran beton yang akan digunakan yaitu Pasir Palu+Kerikil Palu (PPKP), Pasir Palu+Kerikil Petangis (PPKG), Pasir Kandilo+Kerikil Palu (PGKP), Pasir Kandilo+Kerikil Petangis (PKG). Dari hasil pengujian diperoleh kuat tekan rata-rata terbaik pada variasi sampel PPKG yaitu 23,78 MPa dan kuat tekan rata-rata terendah adalah variasi sampel PKG yaitu 17,05 MPa.
\end{abstract}

Kata kunci : Kerikil Petangis, Material local, Pasir Kandilo, Tanah Grogot

\section{PENDAHULUAN}

Tanah Grogot, Kalimantan Timur merupakan ibukota dari Kabupaten Paser. Kecamatan Tanah Grogot merupakan kecamatan dengan luas wilayah terkecil yaitu $335,58 \mathrm{Km}^{2}$ namun memiliki jumlah penduduk terbesar dibandingkan kecamatan lainnya. Saat ini perkembangan dan pembangunan di Tanah Grogot terus meningkat. Selain karena Tanah Grogot merupakan ibukota Kabupaten, hal ini juga dikarenakan jumlah penduduk yang cukup besar yaitu lebih dari 25 persen penduduk Kabupaten Paser bertempat tinggal di Kecamatan Tanah Grogot.
Dalam pelaksanaan pembangunan konstruksi beton, sebagian masyarakat Tanah Grogot menggunakan campuran beton berupa pasir Palu dan kerikil Palu. Namun ada juga masyarakat yang memanfaatkan material local Tanah Grogot berupa pasir Kandilo dan kerikil Petangis. Untuk material local ini belum diteliti terkait kelayakannya sebagai material bangunan. Secara awam masyarakat wilayah Tanah Grogot membuat campuran beton dengan komposisi campuran yang sama tanpa sebelumnya mengetahui karakterisik dari material lokal Tanah Grogot yang digunanakan.

Penelitian ini bertujuan untuk memberikan data terkait karakteristik material local tanah grogot dan 
mendapatkan kuat tekan terbaik untuk perpaduan material bangunan yang umum digunakan oleh masyarakat Tanah Grogot, Kalimantan Timur.

\section{METODE PENELITIAN}

Penelitian yang akan dilakukan berupa eksperimental terhadap sampel silinder beton yang akan diuji pada umur 14 hari dan 28 hari. Dalam membuat campuran beton akan digunakan masingmasing dua jenis pasir dan kerikil. Jenis pasir yang akan digunkan adalah pasir Palu dan pasir Kandilo sebagai material local. Jenis kerikil yang digunakan adalah kerikil Palu dan kerikil Petangis sebagai material local. Ada 4 variasi yang digunakan dalam penelitian ini yaitu : variasi pasir Palu dan kerikil Palu (PPKP), pasir Palu dan kerikil Petangis (PPKG), pasir Kandilo dan kerikil Palu (PGKP) serta pasir Kandilo dan kerikil Petangis (PKG). adalah :

Tahapan yang dilakukan dalam penelitian ini

- Tahap Persiapan : Tahap ini merupakan tahap persiapan yang meliputi persiapan material dan alat penelitian

- Tahap Uji Bahan : Tahap ini bertujuan untuk mendapatkan karakteristik dari material yang akan digunakan. Uji bahan yang dilakukan berupa dari uji pasir dan kerikil. Uji pasir terdiri dari : berat jenis pasir, barat satuan, daya serap air, kandungan lumpur, dan modulus halus butir (mhb). Uji kerikil meliputi : berat jenis kerikil, barat satuan, daya serap air, kandungan lumpur, modulus halus butir (mhb) dan kekerasan.

- Tahap Perencanaan Campuran : Tahap ini merupakan tahap perencanaan campuran beton. Dalam penelitian ini digunakan metode Standar Nasional Indonesia (SNI 03-28342000).

- Tahap Pembuatan dan Perawatan Sampel : Pembuatan sampel silinder beton dibuat berdasarkan hasil mix design. Untuk melihat workability, sebelum dicetak maka dilakukan uji slump. Setelah sampel dalam cetakan kering maka segera dilakukan perawatan beton dengan merendam sampel dalam bak air.

- Tahap Pengujian Sampel : Uji tekan beton dilaksanakan pada umur beton 14 hari dan 28 hari. Prosedur pengujian kuat tekan beton mengacu pada standard ASTM C39-86. Dari hasil uji tekan diperoleh mutu beton.

\section{HASIL DAN PEMBAHASAN}

\author{
Hasil Uji Bahan
}

Hasil uji bahan terhadap pasir Palu, pasir Kandilo, kerikil Palu dan kerikil Petangis seperti pada tabei 1-4.

Tabel 1. Hasil Uji Pasir Palu

\begin{tabular}{|c|c|c|c|c|}
\hline No & Jenis Uji & Syarat & $\begin{array}{c}\text { Hasil } \\
\text { Uji }\end{array}$ & Ket \\
\hline \multirow{2}{*}{1} & $\begin{array}{l}\text { Berat } \\
\text { Jenis }\end{array}$ & $\begin{array}{l}2,5-2,7 \text { (SNI } \\
03-1970- \\
1990)\end{array}$ & 2,50 & $\begin{array}{c}\text { Memenuhi } \\
\text { syarat }\end{array}$ \\
\hline & SSD & $\begin{array}{l}2,5-2,7 \text { (SNI } \\
03-1970- \\
1990)\end{array}$ & 2,51 & $\begin{array}{l}\text { Memenuhi } \\
\text { syarat }\end{array}$ \\
\hline 2 & $\begin{array}{l}\text { Berat } \\
\text { Satuan }\end{array}$ & $\begin{array}{l}1,50-1,80 \\
(\text { SNI 03- } \\
4804-1998)\end{array}$ & 1,80 & $\begin{array}{l}\text { Memenuhi } \\
\text { syarat }\end{array}$ \\
\hline 3 & $\begin{array}{l}\text { Daya } \\
\text { Serap } \\
\text { Air }\end{array}$ & $\begin{array}{l}0,5 \%-1 \% \\
(\text { SNI 03- } \\
1970-1990)\end{array}$ & 2,64 & $\begin{array}{c}\text { Tidak } \\
\text { memenuhi } \\
\text { syarat }\end{array}$ \\
\hline 4 & $\begin{array}{l}\text { Kandung } \\
\text { an } \\
\text { Lumpur }\end{array}$ & $\begin{array}{l}5 \% \text { (PUBI- } \\
1992)\end{array}$ & 0,43 & $\begin{array}{l}\text { Memenuhi } \\
\text { syarat }\end{array}$ \\
\hline 5 & Gradasi & $\begin{array}{l}\text { Mhb 1,5 - 3,8 } \\
(\text { SNI 03- } \\
1968-1990)\end{array}$ & 2,38 & $\begin{array}{c}\text { Memenuhi } \\
\text { syarat }\end{array}$ \\
\hline
\end{tabular}

Berat jenis pasir Palu adalah 2,50 gr/ $\mathrm{cm}^{3}$. Berat jenis jenuh kering permukaan (SSD) sebesar $2,51 \mathrm{gr} / \mathrm{cm}^{3}$. Berdasarkan syarat yang telah ditentukan makan pasir Palu memenuhi syarat yaitu $2,5 \mathrm{gr} / \mathrm{cm}^{3}-2,7 \mathrm{gr} / \mathrm{cm}^{3}$. Berat satuan 1,80 gr/ $/ \mathrm{cm}$, memenuhi syarat $1,50-1,80$. Daya serap air pasir palu tidak memenuhi syarat $0,5 \%-1 \%$ yaitu sebesar 2,64 . Kandungan lumpur $0,43 \%$ memenuhi syarat lebih kecil dari 5\%. Modulus halus butir 2,38 yang berarti memenuhi syarat yaitu $1,5-3,8$.

Tabel 2. Hasil Uji Pasir Kandilo

\begin{tabular}{|c|c|c|c|c|}
\hline No & Jenis Uji & Syarat & $\begin{array}{l}\text { Hasil } \\
\text { Uji }\end{array}$ & Keterangan \\
\hline \multirow{2}{*}{1} & $\begin{array}{l}\text { Berat } \\
\text { Jenis }\end{array}$ & $\begin{array}{l}2,5-2,7 \text { (SNI } \\
03-1970-1990)\end{array}$ & 2,54 & $\begin{array}{l}\text { Memenuhi } \\
\text { syarat }\end{array}$ \\
\hline & SSD & $\begin{array}{l}2,5-2,7 \text { (SNI } \\
03-1970-1990)\end{array}$ & 2,56 & $\begin{array}{l}\text { Memenuhi } \\
\text { syarat }\end{array}$ \\
\hline 2 & $\begin{array}{l}\text { Berat } \\
\text { Satuan }\end{array}$ & $\begin{array}{l}1,50-1,80 \\
(\text { SNI 03-4804- } \\
1998)\end{array}$ & 1,54 & $\begin{array}{l}\text { Memenuhi } \\
\text { syarat }\end{array}$ \\
\hline 3 & $\begin{array}{l}\text { Daya } \\
\text { Serap Air }\end{array}$ & $\begin{array}{l}0,5 \%-1 \%(\mathrm{SNI} \\
03-1970-1990)\end{array}$ & 1,09 & $\begin{array}{c}\text { Tidak } \\
\text { memenuhi } \\
\text { syarat }\end{array}$ \\
\hline
\end{tabular}




\begin{tabular}{cclcc}
\hline 4 & $\begin{array}{l}\text { Kandunga } \\
\text { n Lumpur }\end{array}$ & $\begin{array}{l}5 \% \text { (PUBI- } \\
1992)\end{array}$ & 0,67 & $\begin{array}{c}\text { Memenuhi } \\
\text { syarat }\end{array}$ \\
5 & Gradasi & $\begin{array}{l}\text { Mhb 1,5 - 3,8 } \\
\text { (SNI 03-1968- } \\
1990)\end{array}$ & 2,33 & $\begin{array}{c}\text { Memenuhi } \\
\text { syarat }\end{array}$ \\
\hline
\end{tabular}

Berat jenis pasir Kandilo adalah 2,54 gr/ $\mathrm{cm}^{3}$. Berat jenis jenuh kering permukaan (SSD) sebesar $2,56 \mathrm{gr} / \mathrm{cm}^{3}$. Berdasarkan syarat yang telah ditentukan maka pasir Kandilo memenuhi syarat yaitu $2,5 \mathrm{gr} / \mathrm{cm}^{3}-2,7 \mathrm{gr} / \mathrm{cm}^{3}$. Berat satuan $1,54 \mathrm{gr} /$ $\mathrm{cm}$, memenuhi syarat $1,50-1,80$. Daya serap air pasir kandilo tidak memenuhi syarat $0,5 \%-1 \%$ yaitu sebesar 1,09. Kandungan lumpur 0,67\% memenuhi syarat lebih kecil dari $5 \%$. Modulus halus butir 2,33 yang berarti memenuhi syarat yaitu $1,5-3,8$.

Dari hasil uji bahan pasir terlihat material pasir Palu dan pasir Kandilo memiliki karakteristik yang mendekati.

Tabel 3. Hasil UJi Kerikil Palu

\begin{tabular}{|c|c|c|c|c|}
\hline \multirow[b]{2}{*}{ No } & \multirow[b]{2}{*}{ Jenis Uji } & \multirow[b]{2}{*}{ Syarat } & \multicolumn{2}{|c|}{ Kerilik Palu } \\
\hline & & & $\begin{array}{c}\text { Hasil } \\
\text { Uji }\end{array}$ & Ket \\
\hline \multirow{2}{*}{1} & $\begin{array}{l}\text { Berat } \\
\text { Jenis }\end{array}$ & $\begin{array}{l}2,5-2,7 \text { (SNI } \\
03-1970-1990)\end{array}$ & 2,67 & $\begin{array}{c}\text { Memenuhi } \\
\text { syarat }\end{array}$ \\
\hline & SSD & $\begin{array}{l}2,5-2,7 \text { (SNI } \\
03-1970-1990)\end{array}$ & 2,69 & $\begin{array}{c}\text { Memenuhi } \\
\text { syarat }\end{array}$ \\
\hline 2 & $\begin{array}{l}\text { Berat } \\
\text { Satuan }\end{array}$ & $\begin{array}{l}1,50-1,80 \text { (SNI } \\
03-4804-1998)\end{array}$ & 1,72 & $\begin{array}{c}\text { Memenuhi } \\
\text { syarat }\end{array}$ \\
\hline 3 & $\begin{array}{l}\text { Daya } \\
\text { Serap } \\
\text { Air }\end{array}$ & $\begin{array}{l}0,5 \%-1 \%(\mathrm{SNI} \\
03-1970-1990)\end{array}$ & 0,94 & $\begin{array}{l}\text { Memenuhi } \\
\text { syarat }\end{array}$ \\
\hline 4 & $\begin{array}{l}\text { Kadar } \\
\text { Lumpur }\end{array}$ & $\begin{array}{l}5 \% \text { (PUBI- } \\
1992)\end{array}$ & 0,18 & $\begin{array}{c}\text { Memenuhi } \\
\text { syarat }\end{array}$ \\
\hline 5 & $\begin{array}{l}\text { Ketahan } \\
\text { an Aus }\end{array}$ & $\begin{array}{l}50 \% \text { (SNI 03- } \\
2417-1990)\end{array}$ & $\begin{array}{c}26,94 \\
\%\end{array}$ & $\begin{array}{c}\text { Memenuhi } \\
\text { syarat }\end{array}$ \\
\hline 6 & Gradasi & $\begin{array}{l}\text { Mhb 6,5 - 7,10 } \\
\text { (SNI 03-1968- } \\
\text { 1990) }\end{array}$ & 7,01 & $\begin{array}{l}\text { Memenuhi } \\
\text { syarat }\end{array}$ \\
\hline
\end{tabular}

Berat jenis kerikil Palu adalah 2,67 gr/ $\mathrm{cm}^{3}$. Berat jenis jenuh kering permukaan (SSD) sebesar $2,69 \mathrm{gr} / \mathrm{cm}^{3}$. Berdasarkan syarat yang telah ditentukan makan kerikil Palu memenuhi syarat yaitu $2,5 \mathrm{gr} / \mathrm{cm}^{3}-2,7 \mathrm{gr} / \mathrm{cm}^{3}$. Berat satuan $1,720 \mathrm{gr} / \mathrm{cm}$, memenuhi syarat $1,50-1,80$. Daya serap air kerikil palu memenuhi syarat $0,5 \%-1 \%$ yaitu sebesar 0,94 . Kandungan lumpur 0,18\% memenuhi syarat lebih kecil dari $5 \%$. Ketahanan aus 26,94\% memenuhi syarat kurang dari 50\%. Modulus halus butir 7,01 yang berarti memenuhi syarat yaitu $6,5-7,1$.

Tabel 4. Hasil UJi Kerikil Petangis

\begin{tabular}{|c|c|c|c|c|}
\hline \multirow[b]{2}{*}{ No } & \multirow[b]{2}{*}{ Jenis Uji } & \multirow[b]{2}{*}{ Syarat } & \multicolumn{2}{|c|}{ Kerikil Petangis } \\
\hline & & & $\begin{array}{c}\text { Hasil } \\
\text { Pemeri } \\
\text { ksaan } \\
\end{array}$ & Keterangan \\
\hline \multirow{2}{*}{1} & $\begin{array}{l}\text { Berat } \\
\text { Jenis }\end{array}$ & $\begin{array}{l}2,5-2,7(\mathrm{SNI} \\
03-1970-1990)\end{array}$ & 2,57 & $\begin{array}{c}\text { Memenuhi } \\
\text { syarat }\end{array}$ \\
\hline & SSD & $\begin{array}{l}2,5-2,7 \text { (SNI } \\
03-1970-1990)\end{array}$ & 2,59 & $\begin{array}{c}\text { Memenuhi } \\
\text { syarat }\end{array}$ \\
\hline 2 & $\begin{array}{l}\text { Berat } \\
\text { Satuan }\end{array}$ & $\begin{array}{l}1,50-1,80(\mathrm{SNI} \\
03-4804-1998)\end{array}$ & 1,53 & $\begin{array}{c}\text { Memenuhi } \\
\text { syarat }\end{array}$ \\
\hline 3 & $\begin{array}{l}\text { Daya } \\
\text { Serap } \\
\text { Air }\end{array}$ & $\begin{array}{l}0,5 \%-1 \%(\mathrm{SNI} \\
03-1970-1990)\end{array}$ & 0,78 & $\begin{array}{l}\text { Memenuhi } \\
\text { syarat }\end{array}$ \\
\hline 4 & $\begin{array}{l}\text { Kadar } \\
\text { Lumpur }\end{array}$ & $\begin{array}{l}5 \% \text { (PUBI- } \\
1992)\end{array}$ & 0,19 & $\begin{array}{c}\text { Memenuhi } \\
\text { syarat }\end{array}$ \\
\hline 5 & $\begin{array}{l}\text { Ketahan } \\
\text { an Aus }\end{array}$ & $\begin{array}{l}50 \% \text { (SNI 03- } \\
2417-1990)\end{array}$ & $10,54 \%$ & $\begin{array}{l}\text { Memenuhi } \\
\text { syarat }\end{array}$ \\
\hline 6 & Gradasi & $\begin{array}{l}\text { Mhb 6,5 - 7,10 } \\
\text { (SNI 03-1968- } \\
\text { 1990) }\end{array}$ & 6,84 & $\begin{array}{c}\text { Memenuhi } \\
\text { syarat }\end{array}$ \\
\hline
\end{tabular}

Berat jenis kerikil Petangis adalah 2,57 gr/ $/ \mathrm{cm}^{3}$. Berat jenis jenuh kering permukaan (SSD) sebesar $2,59 \mathrm{gr} / \mathrm{cm}^{3}$. Berdasarkan syarat yang telah ditentukan makan kerikil Petngis memenuhi syarat yaitu $2,5 \mathrm{gr} / \mathrm{cm}^{3}-2,7 \mathrm{gr} / \mathrm{cm}^{3}$. Berat satuan $1,53 \mathrm{gr} /$ $\mathrm{cm}$, memenuhi syarat $1,50-1,80$. Daya serap air kerikil Petangis tidak memenuhi syarat 0,5\%-1\% yaitu sebesar 0,78. Kandungan lumpur 0,19\% memenuhi syarat lebih kecil dari 5\%. Ketahanan aus $10,54 \%$ memenuhi syarat kurang dari $50 \%$. Modulus halus butir 6,84 yang berarti memenuhi syarat yaitu $6,5-7,1$.

Dari hasil uji bahan kerikil terlihat material kerikil Palu dan kerikil Petangis memiliki karakteristik yang mendekati. 1

\section{Hasil Kuat Tekan}

Uji tekan dilakukan pada umur beton 14 hari dan 28 hari. Kuat tekan rata-rata beton pada umur 14 hari adalah 17,05 MPa; 17,28 MPa; 16,60 MPa dan 15,69 MPa berturut-turut untuk variasi sampel PPKP, PPKG, PGKP dan PKG. Hasil uji tekan umur beton 28 hari adalah 22,46 MPa; $23,78 \mathrm{MPa} ; 19,82$ MPa dan 18,12 MPa untuuk bend uji adalah 15,69 MPa untuk variasi sampel PPKP, PPKG, PGKP dan PKG. 


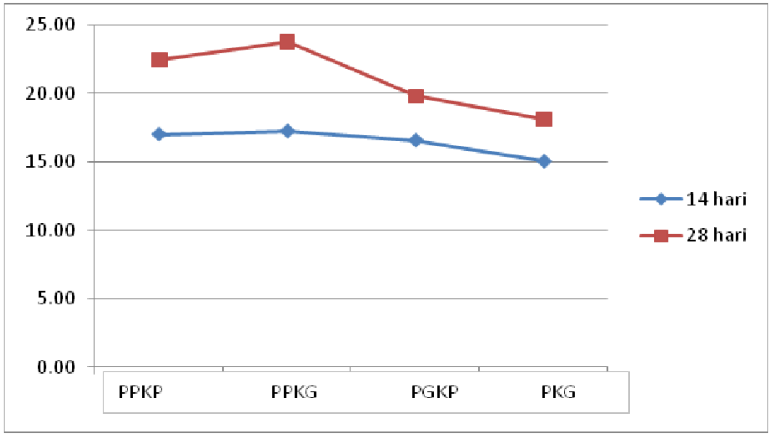

Gambar 1. Grafik hasil Uji Tekan Beton

IUntuk mengamati pengaruh kuat tekan beton pada campuran beton dengan memanfaatkan material local maka perlu dihitung prosentase penigkatan kuat tekan beton terhadap variasi sampel PPKP. Prosentase peningkatan kuat tekan beton umur 14 hari adalah $1,35 \% ;-2,64 \%$ dan $-7,98 \%$ untuk variasi sampel PPKG, PGKP dan PKG terhadap PPKP. Prosentase peningkatan kuat tekan beton umur 28 hari adalah 5,88\%; $-1,75 \%$ dan 19,32\% untuk variasi sampel PPKG, PGKP dan PKG terhadap PPKP.

Pemanfaatan paduan material local pasir Kandilo dan material local kerikil Petangis tidak menghasilkan kuat tekan yang optimal. Namun perpaduan material local kerikil Petangis dengan material pasir Palu menghasilkan kuat tekan ratarata yang lebih baik dibandingkan variasi campuran beton lainnya.

\section{KESIMPULAN DAN SARAN}

Berdasarkan data yang diperoleh dari hasil pengujian beton normal dengan 4 variasi sampel, maka diperoleh kesimpulan sebagai berikut :

- $\quad$ 1Dari hasil uji bahan terlihat material local pasir Kandilo mendekati karakteristik pasir Palu dan karakteristik material local kerikil Petangis mendekati kerikil Palu

- Variasi sampel dengan material campuran pasir Palu + kerikil Petangis (PPKG) memiliki kuat tekan terbaik dibandingkan variasi campuran lainnya yaitu $17,28 \mathrm{MPa}$ dan $23,78 \mathrm{MPa}$ masing-masing untuk umur beton 14 hari dan 28 hari.

Saran yang diberikan dalam penelitian ini adalah :
Sebaiknya dalam membuat campuran beton material local Pasir Kandilo tidak dicampur dengan material kerikil Petangis.

\section{DAFTAR PUSTAKA}

SNI 03-1972-1990 Metode Pengujian Slump Beton SNI 03-2834-2000 Tata Cara Pembuatan Rencana Campuran Beton Normal

Sunarno, 2008. Pemanfaatan Pasir Samboja dan Kerikil asal Palu sebagai Bajan Pembuatan Beton Normal, Tesis, Sekolah Pasca Sarjana Universitas Gajah Mada, Yogyakarta.

Sunarno, 2015. Pemanfaatan Material Lokal Pasir Samboja sebagai Campuran Beton Mutu Tinggi.

Tri Mulyono, 2005. Teknologi Beton, Andi 